\title{
Towards a New HIVIAIDS Policy: Risk Aversion Versus Opportunity Cost
}

\author{
Diana Viljoen
}

School of Economic Sciences, North-West University, Vanderbijlpark, South Africa

Email: Diana.Viljoen@nwu.ac.za

André Mellet

School of Economic Sciences, North-West University, Vanderbijpark, South Africa

Email: Andre.Mellet@nwu.ac.za

\section{Doi:10.5901/mjss.2014.v5n21p305}

\section{Abstract}

The HIVIAIDS pandemic is one of South Africa's greatest challenges. Yet, despite the National HIVIAIDS Strategic Plan (NSP), new HIVIAIDS infections remain high. With reference to the earlier theories of Thomas Malthus, opportunity cost and risk aversion, an interpretive paradigm was followed for this study. Expenditure with regard to the National HIVIAIDS Strategic Plan for South Africa was analysed. The focus of the strategic plan is to reduce HIV infections and also to reduce the impact of the disease by expanding expenditure on medical treatment. This continuous increase in expenditure and the socio-economic effect of the pandemic is analysed. The opportunity cost of risk-seeking behaviour is discussed and possible behavioural change models are proposed. This study shows that, in order to make a significant difference, any HIVIAIDS strategic plan must ensure active prevention rather than passive support. Government must refocus their strategies to incorporate high impact campaigning to make individuals aware of the consequences of HIVIAIDS and reduce the risk-seeking nature of their choices.

Keywords: National HIVIAIDS Strategic Plan, behavioural change theory, opportunity cost

\section{Introduction}

South Africa is a land in crisis. As a developing nation, the control and elimination of the HIVIAIDS pandemic is one of the main challenges facing the country. According to the National HIVIAIDS Strategic Plan (NSP) for South Africa, developed by the Department of Health (2007), it has been estimated that of the 39.5 million people living with HIVIAIDS worldwide, more than $63 \%$ originate from sub-Saharan Africa.

Several factors have been identified as possible causes of the increase in number of new infections. Some of the more common factors are unprotected sexual intercourse and multiple sexual partners (Department of Health, 2007). However, problems such as poverty, low living standards, severe underdevelopment and gender-related issues (including gender bias and gender-based violence) also assist the rampaging pandemic.

In its annual report, the Department of Planning (2010) states that various improvements to the South African HIVIAIDS situation has been recorded, but "....in some cases though the improvements are not as much as we would have liked, for example the infant mortality rate at 44.7 deaths per 1000 live births is not likely to reduce the Millennium Development Goals (MDGs) target of 18 deaths per 1000 live births by 2014. Others show a negative trend, maternal mortality is on the increase largely due to HIV/AIDS, hypertension and obstetric haemorrhage". Despite these small changes, new cases of infection are reported daily. A new strategy must be found to mitigate the social and economic consequences of HIVIAIDS.

This article will, firstly, analyse health expenditure in the NSP in terms of prevention and treatment and the extent of the Health Portfolio in the national budget. Secondly, the socio-economic costs of the pandemic will be discussed. Lastly, behavioural change theories will be analysed. 


\section{HIVIAIDS Expenditure}

\subsection{The National HIV/AIDS Strategic Plan}

An analysis of the NSP for South Africa is necessary in order to identify the different HIVIAIDS expenditure components. The purpose of the NSP is to guide the response to HIV and AIDS (Department of Health, 2007). The strategy draws on experience gained from policies, strategies and programmes implemented before 2006. The intention is to build on the strengths and successes of previous policies, to consider the legal environment, to take cognisance of developments in the scientific field and any changes to international practices, to estimate capacities, to analyse projects for potential achievements, and to identify innovative ways to address weaknesses. The NSP also sets ambitious targets to meet the broad aims of national government. The two main goals of the NSP are to reduce the number of new HIV infections by $50 \%$ and to reduce the impact of HIV and AIDS on individuals, families, communities, and society by expanding access to appropriate treatment, care and support to $80 \%$ of all people diagnosed with HIV (Department of Health, 2007).

The HIVIAIDS pandemic in South African requires a national comprehensive and multi-sectoral response. This response should address the social and economic realities of the most vulnerable societies, provide tools for prevention of the disease, and provide services to mitigate the wide-ranging impacts of the pandemic.

Many factors influence the heterogeneity and high levels of HIVIAIDS prevalence in South Africa. These factors are biological, individual and contextual in nature. Various means of infection exist, but HIVIAIDS is predominantly spread through unprotected sexual intercourse. The contextual factors relate to poverty, gender and gender-based violence, cultural practices, stigma, exclusion and discrimination, labour migration and informal settlements.

Government's plan to reduce the number of new HIVIAIDS infections by $50 \%$ is to be achieved by providing comprehensive care and treatment for people living with the disease and to facilitate the strengthening of the National Health System. As indicated in Table 1, of the funds allocated to managing the HIVIAIDS pandemic, $12 \%$ is earmarked for prevention while the remaining $88 \%$ is purely for providing care and support to those infected with the disease. Clearly Government emphasises passive support through treatment rather than rigorous proactive prevention campaigns.

Of the $12 \%$ allocated to prevention, $50 \%$ is geared toward behavioural change interventions (prevention). Since the number of infections increase regardless of the interventions, the question arises as to whether these interventions are providing the impact necessary to facilitate the risk reducing behaviour required to reduce the number of new infections. The data in Table 1 seems to provide the HIVIAIDS scenario with an air of complacency with passive treatment emphasised over active and rigorous prevention campaigns. As long as treatment is available, the pandemic is manageable and its seriousness is tempered by perfunctory prevention campaigns. Treatment, while necessary, does not expound the socio-economic consequences of the disease.

When analysing the care, support and health portion of the HIVIAIDS budget the largest cost item is adult antiretroviral treatment, which amounts to $40 \%$ of the total cost in the low-cost scenario (this is assuming that only $60 \%$ of new HIVIAIDS cases would receive antiretroviral treatment by 2011). The other "big cost" items are food support for adults (9\%), antiretroviral treatment for children (7\%) and the support of orphans and vulnerable children at $6 \%$ of the total cost. In the prevention portion, which amounts $12 \%$ of the total cost in the low cost scenario, behavioural change interventions constitute only $6 \%$. In the high-cost scenario (based on the assumption that $80 \%$ of new HIVIAIDS cases receive antiretroviral treatment by 2011) the ratio between the various cost items is similar to that of the low-cost scenario. 
Table 1: HIVIAIDS expenditure by category

\begin{tabular}{|c|c|c|c|c|c|c|c|c|}
\hline \multirow{2}{*}{ Priority area } & \multirow{2}{*}{ Goal } & \multirow{2}{*}{ Intervention } & \multicolumn{6}{|c|}{ Year } \\
\hline & & & 2007 & 2008 & 2009 & 2010 & 2011 & $\%$ Total \\
\hline \multicolumn{3}{|l|}{ Prevention } & 643 & 792 & 951 & 1098 & 1247 & 12 \\
\hline \multicolumn{3}{|c|}{ Reduce sexual transmission } & 642 & 790 & 949 & 1097 & 1245 & 12 \\
\hline \multicolumn{3}{|c|}{ Behavioural change interventions } & 300 & 400 & 500 & 600 & 700 & 6 \\
\hline \multicolumn{3}{|c|}{ Condom provision } & 145 & 152 & 172 & 180 & 188 & 2 \\
\hline \multicolumn{3}{|c|}{ Life skills } & 158 & 168 & 177 & 186 & 195 & 2 \\
\hline \multicolumn{3}{|c|}{ PEP for sexual assault } & 0 & 10 & 11 & 11 & 12 & 0 \\
\hline \multicolumn{3}{|c|}{ STI management } & 30 & 60 & 90 & 120 & 150 & 1 \\
\hline \multicolumn{3}{|c|}{ Reduce transmission through occupational exposure } & 1 & 1 & 1 & 1 & 1 & 0 \\
\hline \multicolumn{3}{|c|}{ PEP for occupational exposure } & 1 & 1 & 1 & 1 & 1 & 0 \\
\hline \multicolumn{3}{|c|}{ Care, support and health system strengthening } & 4042 & 5612 & 6960 & 8474 & 10012 & 88 \\
\hline \multicolumn{3}{|c|}{ Scale-up access to VCT } & 260 & 420 & 423 & 426 & 428 & 5 \\
\hline \multicolumn{3}{|c|}{ HIV testing } & 260 & 420 & 423 & 426 & 428 & 5 \\
\hline \multicolumn{3}{|c|}{ Maintain health of HIV-infected adults } & 2495 & 3365 & 4250 & 5301 & 6360 & 55 \\
\hline \multicolumn{3}{|c|}{ Antiretroviral treatment for adults } & 1588 & 2296 & 3115 & 4036 & 5014 & 40 \\
\hline \multicolumn{3}{|c|}{ Food support for adults } & 521 & 586 & 652 & 782 & 912 & 9 \\
\hline \multicolumn{3}{|c|}{ Home and community based care } & 386 & 483 & 483 & 483 & 435 & 6 \\
\hline \multicolumn{3}{|c|}{ Address the special needs of mothers and children } & 1007 & 1267 & 1447 & 1627 & 1823 & 18 \\
\hline \multicolumn{3}{|c|}{ Antiretroviral treatment for children } & 245 & 359 & 488 & 635 & 791 & 6 \\
\hline \multicolumn{3}{|c|}{ OVC } & 452 & 561 & 589 & 618 & 649 & 7 \\
\hline \multicolumn{3}{|c|}{ PMTCT dual therapy \& infant testing } & 310 & 348 & 370 & 374 & 383 & 4 \\
\hline \multicolumn{3}{|c|}{ Strengthen the health system } & 280 & 560 & 840 & 1120 & 1400 & 11 \\
\hline \multicolumn{3}{|c|}{ Strengthen TB programme management } & 30 & 60 & 90 & 120 & 150 & 1 \\
\hline \multicolumn{3}{|c|}{ Increase $\mathrm{CHC}$ coverage } & 250 & 500 & 750 & 1000 & 1250 & 9 \\
\hline \multicolumn{3}{|l|}{ Grand total } & 4685 & 6404 & 7910 & 9572 & 11259 & 100 \\
\hline
\end{tabular}

Source: Department of Health (2007)

\subsection{National Health Budget}

South Africa has the largest number of people enrolled in antiretroviral therapy in the world (Department of Health, 2007). This increased demand for treatment places strain on the scarce capital resources of government. As a result, the health budget has become the second biggest portfolio in the national budget.

In 2009, Trevor Manuel (National Treasury, 2009), the previous Minister of Finance, stated "We are profoundly conscious of the complexity of the challenges facing our health services and the strain on resources associated with a rising disease burden. ...The tuberculosis and HIV and AIDS programmes both receive additional resources". Budget expenditure on treatment increased in order to provide for over 700000 more individuals. Spending on HIV increased from R 8 billion in 2008 to R 11 billion in 2009 (SANAC, 2012). The 2010 national budget increased expenditure on HIV and AIDS programmes by R 5.4 billion and R 3 billion for those co-infected with tuberculosis (TB) and CD4 counts lower than 350 (National Treasury, 2010). In 2011, the national budget incorporated funding (over R 8 billion) for the National Health Insurance (NHI) scheme. Total spending on the HIVIAIDS conditional grant, which is aimed toward treatment, amounted to R 26.9 billion over the medium term expenditure framework (MTEF). The national budget for the years 2012-2014 were dominated by expenditure on the NHI and increased funding for treatment and medication rollout.

Table 2 shows that the number of HIVIAIDS infections did not decline despite the interventions proposed by the NSP. The long term goal of reducing the number of new HIVIAIDS infections by $50 \%$ will be hard to achieve should this trend continue. Data for the years 1994-2000 were not available as HIVIAIDS in South Africa was, as yet, not treated as the pandemic it has since become (Avert, 2011). 
Table 2: HIVIAIDS prevalence

\begin{tabular}{|c|c|c|c|c|c|c|c|c|c|c|}
\hline Year & $\begin{array}{c}\text { Youth } \\
\mathbf{1 5 - 2 4}\end{array}$ & $\begin{array}{c}\text { Adult women } \\
\mathbf{1 5 - 4 9}\end{array}$ & $\begin{array}{c}\text { Adult women } \\
\mathbf{2 0 - 5 4}\end{array}$ & $\begin{array}{c}\text { Adult men } \\
\mathbf{2 0 - 6 4}\end{array}$ & $\begin{array}{c}\text { All adults } \\
\mathbf{2 0 - 6 4}\end{array}$ & $\begin{array}{c}\text { Total } \\
\text { female pop. }\end{array}$ & $\begin{array}{c}\text { Total male } \\
\text { pop. }\end{array}$ & $\begin{array}{c}\text { Total } \\
\text { pop. }\end{array}$ & $\begin{array}{c}\text { Women attending } \\
\text { antenatal care }\end{array}$ & $\begin{array}{c}\text { HIV prevalence: } \\
\text { ASSA model }\end{array}$ \\
\hline $\mathbf{1 9 9 4}$ & & & & & & & & & 7.6 & \\
\hline $\mathbf{1 9 9 5}$ & & & & & & & & & 10.4 & \\
\hline $\mathbf{1 9 9 6}$ & & & & & & & & & 14.2 & \\
\hline $\mathbf{1 9 9 7}$ & & & & & & & & & 17.0 & \\
\hline $\mathbf{1 9 9 8}$ & & & & & & & & & 22.5 & \\
\hline $\mathbf{1 9 9 9}$ & & & & & & & & & 22.4 & \\
\hline $\mathbf{2 0 0 0}$ & & & & & & & & & 24.5 & \\
\hline $\mathbf{2 0 0 1}$ & 9.2 & 18.7 & 19.2 & 14.2 & 15.4 & 10.8 & 7.8 & 9.4 & 24.8 & \\
\hline $\mathbf{2 0 0 2}$ & 9.9 & 19.2 & 19.3 & 14.0 & 15.8 & 11.2 & 7.9 & 9.6 & 26.5 & 7 \\
\hline $\mathbf{2 0 0 3}$ & 9.9 & 19.4 & 19.6 & 14.0 & 16.1 & 11.5 & 8.0 & 9.8 & 27.9 & 8 \\
\hline $\mathbf{2 0 0 4}$ & 10.4 & 19.6 & 19.9 & 14.0 & 16.3 & 11.7 & 8.1 & 9.9 & 28.5 & 9 \\
\hline $\mathbf{2 0 0 5}$ & 10.5 & 19.7 & 20.0 & 13.9 & 16.5 & 11.8 & 8.1 & 10.0 & 30.2 & 9 \\
\hline $\mathbf{2 0 0 6}$ & 10.3 & 19.7 & 20.2 & 13.9 & 16.6 & 11.9 & 8.2 & 10.1 & 29.10 & 10 \\
\hline $\mathbf{2 0 0 7}$ & 10.2 & 19.7 & 20.3 & 13.8 & 16.7 & 12.0 & 8.2 & 10.2 & 29.40 & 10 \\
\hline $\mathbf{2 0 0 8}$ & 10.0 & 19.7 & 20.3 & 13.8 & 16.9 & 12.1 & 8.3 & 10.3 & 29.30 & 10 \\
\hline $\mathbf{2 0 0 9}$ & 9.9 & 19.5 & 20.3 & 13.7 & 17.0 & 12.2 & 8.3 & 10.3 & & 11 \\
\hline $\mathbf{2 0 1 0}$ & 10.1 & 19.7 & 20.4 & 13.8 & 17.3 & 12.4 & 8.5 & 10.5 & & 11 \\
\hline
\end{tabular}

Source: Department of Planning (2010)

\section{Socioeconomic Effects of HIVIAIDS}

In order to fully understand the impact that HIVIAIDS has on the average South African, an analysis of the socioeconomic impact of the disease must be carried out. Developing countries are often crippled by the burden of disease, whether HIVIAIDS, TB or Malaria. Even though South Africa is more advanced than most other African nations, it faces one of the highest HIV prevalence rates in the world. As indicated by Perkins, Radelet and Lindauer (2006), there is a direct relationship between health and economic growth, income levels and poverty.

A healthier population gives rise to higher economic growth rates and a lower level of poverty. This statement is contravened by the mere existence of HIVIAIDS in society. According to a study conducted by UNAIDS (2009), $18.3 \%$ of individuals aged 15-46 years old are infected with HIV. This figure is lower than the 24.1\% (across those aged 20-65 years old) indicated by the ASSA2000 model developed by the Actuarial Society of South Africa (ASSA, 2011). Clearly, the HIVIAIDS pandemic predominantly affects the economically active members of a population. With developing economies, such as South Africa, where the majority of the population is involved in work that requires a high level of physical activity (agriculture, mining, manufacturing, etc.) any disease that hampers the health of a population will affect the output within an economy and, as a result, the rate of economic growth.

Bollinger and Stover (1999) state that the impact of HIVIAIDS on a household starts immediately after a diagnosis has been made. As the main income earners within a household become ill, other household members take time off to care for the sick individual. Less time is spent on income-generating activities and as a result, household income starts to decline. At the same time, household expenditure starts to rise as a result of increased medical costs. If available income is swallowed up by managing the disease, the family concerned would in all likelihood, be reduced to abject poverty.

AIDS is one of the main causes of premature deaths in South Africa during the period 1997-2004 with mortality rates increasing by $79 \%$ (Department of Health, 2007). A higher rate of increase in mortality was found in women than men. AIDS is also responsible for $50 \%$ of the number of orphans within the country.

Increased poverty as a result of disease has effects that are even more devastating than the disease itself. With the main income earner of a household suffering from HIVIAIDS, the other members of the family must compensate for the loss of income. Children within the household are often forced to drop out of school to care for the sick family member or to earn extra money. As a result, education is hindered.

Todaro and Smith (2003) state that education is a necessary component in the adoption and maintenance of new technologies and processes and, in so doing, developing nations develop the capacity for economic growth and sustainable development. However, in most cases, the opportunity cost of labour is higher than that of education for families affected by HIVIAIDS. Even if education was completely free, children would be required to supplement lost 
income or provide care for sick family members.

The causal relationship between health and education can also be reversed. An individual who has a higher level of education will have a greater impact on his/her surroundings. Parents with a higher level of education will have greater insight into the importance of hygiene and when dealing with HIVIAIDS, the importance of abstinence, the use of prophylactics and ensuring that their children are aware of the inherent dangers and consequences of the disease.

By increasing the mortality rate, HIVIAIDS not only affects the productivity of workers living with the disease but also the overall productivity of the undertaking concerned. According to Perkins et al. (2006), people who are healthier tend to be more economically active because they are more energetic and mentally alert. HIVIAIDS also affects the availability of skilled workers due to the changes incurred in the economically active population of the economy. Available labour supply becomes younger and those with the prerequisite experience and skill sets become rare. Labour laws in South Africa also prevent employers from retrenching workers who are unable to perform due to disease. This in turn, affects the productivity and output of the undertaking concerned and impacts negatively on the competitiveness of South African products.

Haacker (2004), states that companies often have to carry a higher monetary burden as a result of HIVIAIDS. Direct costs such as higher death and medical benefits, as well as indirect costs such as training of new staff to fill positions vacated by sick staff members and possible loss in productivity, can be incurred by the company. The increased cost of inputs to the production process will prompt the producer to shift the burden of the cost over to the consumer by increasing the price of the product or service. In an inflationary economic climate, this process will contribute towards a depreciation of the domestic currency.

Government expenditure is also influenced negatively due to HIVIAIDS. Government expenditure increases as a result of the increased demand for public health services. The opportunity cost of government expenditure comes into question. Instead of increased expenditure on the provision of essential public goods, for example, building new infrastructure, increased capacity in essential sectors of the economy and support for new entrepreneurs, the emphasis is placed on treatment campaigns and health programmes. Booysen et al. (2003) indicates that an increase in social grants (in the form of child grants issued to children orphaned by the disease) would also increase expenditure by the public sector.

A substantial amount of resources are being directed towards provision of medication and care programmes, state Arndt and Lewis (2000). These resources carry a high opportunity cost as available income is being directed away from the provision of essential public goods and services towards managing the epidemic. With a shrinking tax base due to increased mortality of those living with the disease, this has a profound impact on the ability of the public sector to provide public goods and services.

The disruption in the provision of public services as a result of HIVIAIDS occurs in a similar manner to that of the private sector. Productivity of public sector employees starts to decline as more employees become ill. Expenditure by public sector employees starts to increase as more existing staff are replaced by new employees that must be trained in order to fill the vacant positions.

The increased expenditure and loss of human capital experienced by the public sector compromises the balance of payments on both the revenue and expenditure side. Increased demand for health services places a strain on revenue collected by the government and the provision of other public goods and services.

While the provision of health services is essential, there needs to be a more aggressive approach to managing the HIVIAIDS pandemic. With so many South Africans facing the social and economic consequences of HIVIAIDS government should reprioritise budgetary focus in order to preserve South Africa for future generations of South Africans.

\section{Behavioural Change Theories}

\subsection{Malthusian hypotheses}

Thomas Malthus, known for his theories regarding population growth, transposed the laws of nature to human society. According to Moss (2005), Malthus hypothesised that there is an instinctual human drive to further one's genetic line. In so doing, according to Lee and Loschky (1987), population growth has the potential to increase exponentially, while food production only increases arithmetically. To counter this, and to ensure equilibrium between population growth and the ability of land to provide sustenance, certain checks exist. These checks are either preventative or positive in nature. Positive checks, that raise the mortality rate, include war, disease, famine and any occurrence that reduces the population. Preventative checks, that lower the birth rate, include birth control, abstinence and any action that reduces the birth rate. 
Malthus further stated that the supply of food beyond a subsistence level will eventually be consumed by an ever increasing population. It would not be possible for minimum standards of living and income per capita to remain at a subsistence level for the majority of the population in the long run. In his words "...the power of population growth is so superior to the power of the earth to produce subsistence for man that premature death must in some shape or other visit the human race" (Lee \& Loschky, 1987).

According to Waterman (1992), in the third revision of his theory, Malthus included a moral aspect to his argument. He advocated restraint and delayed marriage if the intended couple could not provide for their offspring. By ensuring that the family unit did not exceed the maximum expenditure that it could manage with its given income, the family would then be able to maximise its consumption of those goods and services beneficial to enhancement of their living standards. These beneficial goods and services included health care and education amongst others. Malthus believed that the prudential considerations he advocated would ensure the amelioration of the labour class and a consistent rise in the living standards of the population at large. Malthus would see today's pandemic as a positive check toward reducing the world's population, a cruel but inevitable fate. Despite the criticisms levelled at his theory, Malthus refuted all naysayers by stipulating that morality is the catalyst for the improvement of living standards.

To modern society, Malthus was governed by unrealistic ideals that are controversial in nature and do not hold to modern ideals and social practices.

\subsection{Opportunity cost}

Mohr and Fourie (2004), state that the opportunity cost of a decision is the value of the choice that was not taken. Smit et al. (1997), state that opportunity cost is the value of the alternative opportunities that are lost. While the moral issue behind marriage and sexual intercourse still exist, the socioeconomic consequences of risk-seeking behaviour, namely unprotected sexual intercourse, are now at the forefront of society's decision-making process. For individuals, one must make the choice between a disease-free existence and the potential for contracting a life-threatening disease. For government, policymakers must make a choice between supplying medicine (increasing HIVIAIDS expenditure components in the Health Portfolio) or prevention campaigns that could limit capital expenditure in the annual budget so as to spend scarce resources in the most economical way.

\subsection{Risk-reducing behaviour}

The Office of Technology Assessment (OTA, 1995) in the United States of America has cited behavioural change as a means of preventing all future HIV transmissions. While no prevention campaign will ever be completely effective, even a slight delay in the possibility of infection would indicate success for the campaign concerned. The transmission of the disease is dependent on an individual's behaviour. If one is risk-seeking, then unprotected intercourse would be preferred. The reverse would also be true.

While HIVIAIDS is now being portrayed as a manageable disease, one should ask if society at large is aware of all the socioeconomic setbacks experienced by those living with the disease. Prevention campaigns do little in the way of informing society of the lost income as a result of lower worker hours that are a consequence of sickness or the stigma that is attached to being HIV-positive. These messages often have to compete with human desires and the social pressures of being sexually active.

Fisher and Fisher (1992) proposed a three-factor conceptualisation of AIDS-preventive behaviour. In this model information, motivation and behavioural skills are the key components needed to reduce the risk of HIVIAIDS infections.

In this model, information regarding the means of transmission of the disease and methods of preventions are prerequisites for reducing the risk of infection. Society should be informed of all the consequences of risky-seeking behaviour and should be made aware of the socio-economic consequences of their decisions. Motivation to change behaviour with regards to the disease is the second determinant of prevention. Here, the emphasis must be placed on why the individual should change their risky behaviour (highlighting factors such as increased health cost, decreased living standards and the potential increase in poverty rates). Lastly, the behavioural skills needed to implement risk reducing behaviour should be taught. The individual should learn how to communicate and be assertive with partners (particularly in the case of condom use and other forms of prophylaxis). The need for restraint and foresight when making decisions that could impact an individual's HIV status should be highlighted. Here, opportunity cost principles can be applied in order to weigh the outcomes of each possible decision, namely, engaging in risky sexual practices and risk infection or use restraint avoid potential exposure. 


\section{Conclusion}

Awareness and rigorous prevention campaigns should play a major role in changing the AIDS-risk behaviour of individuals. According to the current health plan of South Africa, a greater percentage of expenditure (88\%) is granted for treatment of HIVIAIDS than prevention (12\%) of the disease itself. The last three budgets in the health plan period stated an increase in health capital requirements and an increase in the supply of medication (antiretrovirals). This is clearly not an effective strategy when taking into account that more than $15 \%$ of the economically active population in South Africa are affected with HIV. By educating individuals about the consequences of HIVIAIDS and providing them with the tools and training needed to perform AIDS-preventative acts, the rate of infection within the country can be reduced. If society is not re-orientated toward reducing risk-seeking behaviour, then HIV will not decline.

Since 2010, the South African government is has been conducting impact and cost studies relating to a new National Health Insurance plan. According to Government, this proposed plan will require substantial reforms to address imbalances across the public and private sectors. This proposal proves that the current system cannot cope with the large demand for health services in the country.

Life is governed by choices. In the current scenario, individuals need to be made aware of the consequences of the HIVIAIDS in order to make informed choices regarding sexual activity. Government must choose a better mix of policy actions in order to ensure reduced numbers of new infections and capital expenditure on health care. Reducing risky behaviour now will not only reduce expenditure on prevention but also preserve the South African economy for successive generations who are born free of the tyranny of HIVIAIDS.

\section{References}

Arndt, C. \& Lewis, J.D. (2000). The macro implications of HIVIAIDS in South Africa: a preliminary assessment. South African Journal of Economics, 68(5): 856 - 887.

Avert. (2011). History of HIV and AIDS in South Africa. [Online] Available: http://www.avert.org/history-hiv-aids-south-africa.htm (July 25, 2014)

Bollinger, L. \& Stover, J. (1999). The economic impact of AIDS in South Africa. Washington: USAID.

Booysen, F., Geldenhuys, J.P. \& Marinkov, M. (2003). The impact of HIVIAIDS on the South African economy: a review of current evidence. Free State: University of the Free State.

Fisher, J.D. \& Fisher, W.A. (1992). Changing AIDS-risk behaviour. Connecticut: University of Connecticut.

Haacker, M. (2004). HIVIAIDS: the impact on the social fabric and the economy. In M. Haacker (Ed.), The macroeconomics of HIVIAIDS (pp 41-95). Washington: IMF.

Lee, M.L. \& Loschky, D. (1987). Malthusian population oscillations. Economics Journal, 97(387): 727 - 739.

Mohr, P. \& Fourie, L. (2004). Economics for South African Students. 3rd ed. Pretoria: Van Schaik Publishers.

Moss, L.S. (2005). Playing Fast and Loose with the Facts about the writings of Malthus and the Classical School. History of the Political Economy, 37(2): 211 - 218.

National Treasury. (2009). Budget Speech. Pretoria: Government Printer.

National Treasury. (2010). Budget Speech. Pretoria: Government Printer.

National Treasury. (2011). Budget Speech. Pretoria: Government Printer.

Office of Technology Assessment. (1995). The effectiveness of AIDS prevention efforts. Washington: Congress of the United States.

Perkins, D.H., Radelet, S. \& Lindauer, D.L. (2006). Economics of development. New York: Norton.

SANAC (South African National AIDS Council). (2012). South African National AIDS Spending Brief. [Online] Available: http://www.sanac.org.za/resources/aids-spending/cat_view/6-aids-spending (July 25, 2014)

Smit, P.C., Dams, D.J., Mostert, J.W, Oosthuizen, A.G., Van der Vyver, T.C. \& Van Gass, W. (1997). Economics: A Southern African Perspective. Kenwyn: Juta \& Co.

Department of Health. (2007). National HIVIAIDS Strategic Plan (2007-2011). Pretoria: Government Printer.

Department of Planning. (2010). Annual report. Pretoria: Government Printer.

Todaro, M.P. \& Smith, S.C. (2003). Economic Development. London: Pearson.

UNAIDS. (2009). UNAIDS report on the global AIDS epidemic. Geneva: United Nations.

Waterman, A.M.C. (1992). Analysis and Ideology in Malthus's essay on population. Australian Economic Papers, 31 (58): 203 - 217. 
